\title{
A light and electron microscopic study of the liver in case of erythrohepatic protoporphyria and in griseofulvin-induced porphyria in mice
}

\author{
A. MATILla AND ElizABETH A. MOLLAND \\ From the Institute of Pathology, The London Hospital
}

SYNOPSIS The light- and electron-microscopic appearances of a liver biopsy from a case of erythrohepatic protoporphyria are compared with the appearances of the liver in griseofulvin-induced porphyria in mice. Crystals are present in hepatocytes and in the bile secretory pathways in each case. The nature and significance of these is discussed.

The porphyrias may be classified as 'hepatic' or 'erythropoietic' according to whether the liver or bone marrow is the principal site of disturbed porphyrin metabolism (Schmid, Schwartz, and Watson, 1954). Usually included in the erythropoietic group is the inherited disorder erythropoietic protoporphyria (EPP) first described by Magnus, Jarrett, Prankerd, and Rimington (1961). It presents with photosensitivity and is characterized by an excess of protoporphyrin in the circulating erythrocytes and in the stools. The site of the principal lesion is not yet known but present evidence suggests the existence of a hepatic as well as an erythropoietic lesion. Following reports of intrahepatic deposits of protoporphyrin in erythropoietic protoporphyria by Cripps and Scheuer (1965), cases of cirrhosis and liver cell failure have been described (Barnes, Hurworth, and Millar, 1968; Donaldson, McCall, Magnus, Simpson, Caldwell, and Hargreaves, 1971; Schmidt and Stich, 1971; Thompson, Molland, Nicholson, and Gray, 1973), and the term 'erythrohepatic protoporphyria' has been suggested (Donaldson et al, 1971) as a more comprehensive description of the disease.

A disturbance of porphyrin metabolism characterized by biochemical changes similar to those of human erythropoietic protoporphyria and the deposition of protoporphyrin in liver cells follows the administration of griseofulvin to mice (De Matteis and Rimington, 1963; Weston-Hurst and Paget 1963), and 3:5-dicarbethoxy 1:4-dihydrocollidine (DDC) to guinea pigs, star and to weanling pigs (Granick and Urata, 1963; Magnus, Roe, and Received for publication 30 May 1974.
Bhutani, 1969; Roe, Krook, and Wilkie, 1970). We have studied the light microscopic and ultrastructural appearances of a liver biopsy from a patient with erythropoietic protoporphyria who had abs normal liver function tests and have compared then with the morphological changes in the livers of mice during the development of griseofulvin-induce porphyria.

\section{Materials and Methods}

\section{CASE REPORT}

A 30-year-old women had a history of photosensitivity for nine months. She had been taking the pill (Gynovlar) regularly for the previous 18 months.

\section{Laboratory investigations}

Haemoglobin $12.4 \mathrm{~g} / 100 \mathrm{ml}$; ESR $41 \mathrm{~mm}$ in the first hour; alkaline phosphatase, $16.0 \mathrm{King}$-Armstrong units $/ 100 \mathrm{ml}$; serum glutamic oxaloacetic transaminase. $50 \mathrm{I}$ units $/ 100 \mathrm{ml}$ (normal upper limit $40 \mathrm{I}$ units $/ 100 \mathrm{ml}$ ); bilirubin $0.8 \mathrm{mg} / 100 \mathrm{ml}$.

The bromsulphthalein/retention test showed $15 \%$ retention at 45 minutes (normal: less than $5 \%$ ).

\section{Red cell porphyrins}

First specimen: protoporphyrin $219.5 \mu \mathrm{g} / 100 \mathrm{ml}$, coproporphyrin $5 \mu \mathrm{g} / 100 \mathrm{ml}$; Second specimen: protoporphyrin $232 \mu \mathrm{g} / 100 \mathrm{ml}$, coproporphyrin $3.4 \mu \mathrm{g} / 100 \mathrm{ml}$ (normal: protoporphyrin $3.5-30 \mu \mathrm{g} /$ $100 \mathrm{ml}$, coproporphyrin $0 \cdot 4-4 \cdot 1 \mu \mathrm{g} / 100 \mathrm{ml}$ ).

\section{Faecal porphyrins}

First specimen: protoporphyrin $1578 \mu \mathrm{g} / \mathrm{g}$ of dry 
weight stool, coproporphyrin $51 \mu \mathrm{g} / \mathrm{g}$; second specimen: protoporphyrin $567 \mu \mathrm{g} / \mathrm{g}$, coproporphyrin $31 \mu \mathrm{g} / \mathrm{g}$ (normal: protoporphyrin $0-113 \mu \mathrm{g} / \mathrm{g}$, coproporphyrin 0-50 $\mu \mathrm{g} / \mathrm{g}$ ). ' $\mathrm{X}$ ' porphyrins: normal.

Screening tests on faecal porphyrins from several relatives were normal. Biopsy of skin from the hand showed PAS-positive hyaline material around the papillary vessels, characteristic of erythropoietic protoporphyria.

Skin tests with narrow waveband artificial ultraviolet light (Magnus, Porter, McCree, Moreland, and Wright, 1959) showed abnormal reactions at $360,380,400$, and $500 \mathrm{~m} \mu$. Ultraviolet microscopy of peripheral blood films revealed occasional fluorescent red cells.

\section{Liver biopsy}

This was performed because of the abnormal liver function tests.

The biopsy measured $1.7 \mathrm{~cm}$ in length. A portion was postfixed in $1 \%$ osmium tetroxide and embedded in araldite. Ultra-thin sections were stained by uranyl acetate and lead citrate, and examined in the AE1 EM6B electron microscope. As a reference for the ultrastructural studies $1-2 \mu$ sections were stained with toluidine blue. The remainder of the material was fixed in $4 \%$ formal saline, paraffin embedded, and $5 \mu$ sections were stained with haematoxylin and eosin, Gordon and Sweet's reticulin, Perls' Prussian blue, Fouchet, periodic acid-Schiff, Verhoeff-van Gieson, and Sudan Black. Unstained sections were examined under ultraviolet light, using a mercury vapour light source and a Schott BG 12 primary filter with a barrier cut off at $500 \mathrm{~m} \mu$.

\section{ANIMAL STUDIES}

Twenty male mice weighing about $25 \mathrm{~g}$ at the beginning of the experiment were given a standard powdered diet of Thompson's mixture and water ad libitum. After one week griseofulvin was added as a

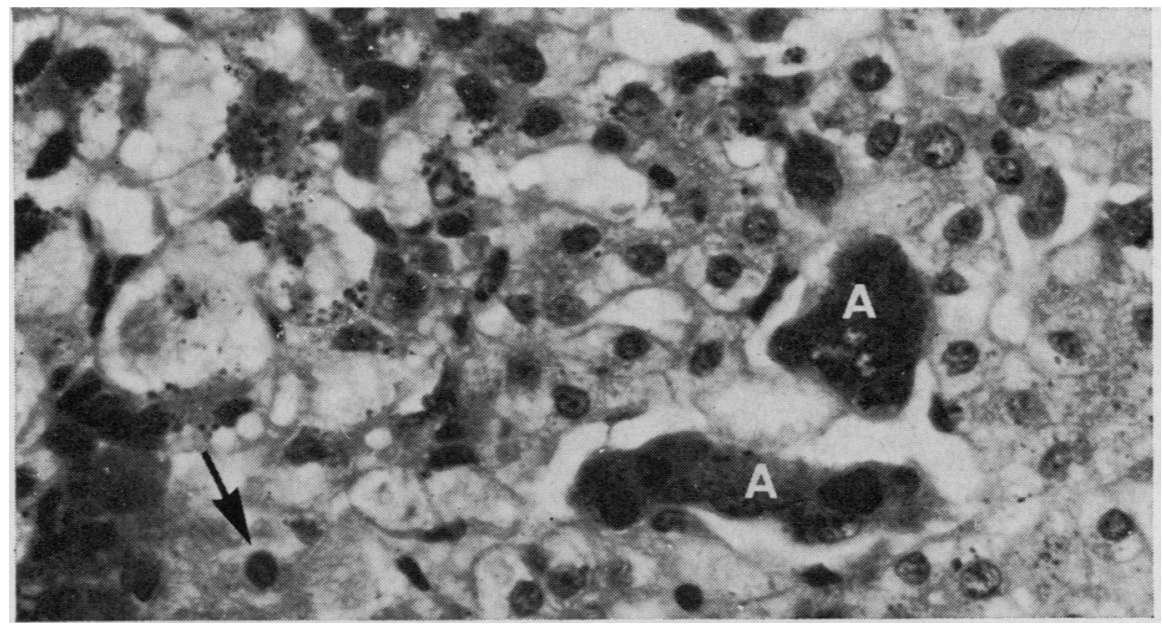

Fig 1a Human liver: granules in hepatocyte cytoplasm, thrombi in canaliculi (arrowed), pigment in Kupffer cells (A). $H \& E \times 140$.

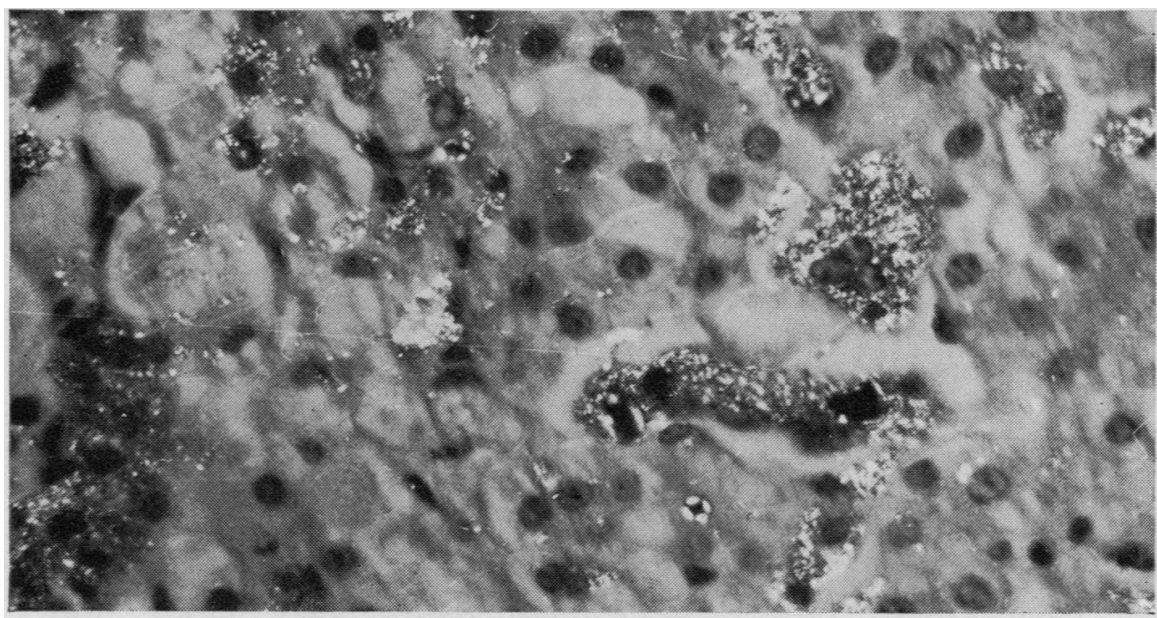

Fig 1b Viewed under polarized light: birefringent granules and Maltese crosses. 
$2.5 \%$ mixture by weight to the diet of 10 of the animals. Thereafter they were sacrificed at intervals, beginning at 24 hours, and the experiment was completed five weeks later. Frozen sections of each liver were examined immediately under ultraviolet light. A portion of each was fixed in $2 \%$ glutaraldehyde, postfixed in osmium tetroxide, and processed as above for ultrastructural examination. The remainder was fixed in $4 \%$ formal saline, and treated in the same way as the human material for light microscopic examination.

\section{Results}

\section{LIVER BIOPSY IN HUMAN ERYTHROHEPATIC PROTOPORPHYRIA}

\section{Light microscopy}

The architecture of the liver was normal. Deep redbrown granules were present within some of the hepatocytes, chiefly in the periportal areas and to a lesser extent around central veins. Groups of cells showed swelling with vacuolation of their cytoplasm. Kupffer cells were prominent, due to large amounts of dark brown pigment in their cytoplasm. Some had formed multinucleate cells. Many canaliculi and bile ducts were occluded by dark brown thrombi (fig 1a). Pigment-containing macrophages and scanty lymphocytes were also observed in the portal tracts. Occasional inclusions were also observed in Kupffer cells and macrophages. There was

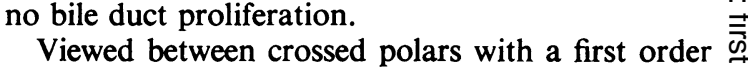
quartz red compensator in position, weakly positively birefringent pigment was seen within hepatocytes, Kupffer cells, and macrophages (Bloomer, Davidson, and Klatskin, 1973). 'Maltese cross' figures were seen in some of the thrombi, and in the larger granules in the hepatocytes (fig 1b).

Fouchet's stain demonstrated bile in varying amounts in most of the inclusions. The pigment was PAS-positive, negative for iron, and Sudan Black negative.

Examination of the pigment using ultraviolet light revealed that it emitted dull red fluorescence io which was strongest in the pigment masses in the Kupffer cells and macrophages. Thrombi did not $\infty$ exhibit fluorescence at their centres, but had a rim 은 of red fluorescence. There was no diffuse cytoplasmic fluorescence, but some of the hepatocyte granules exhibited weak fluorescence.

\section{Electron microscopy of hepatocytes}

The nuclei, endoplasmic reticulum and Golgi apparatus were normal. The mitochondria showe slight variation in size and measured up to $2-3 \mu$ 通 length: some had lost some of their cristae and mang.

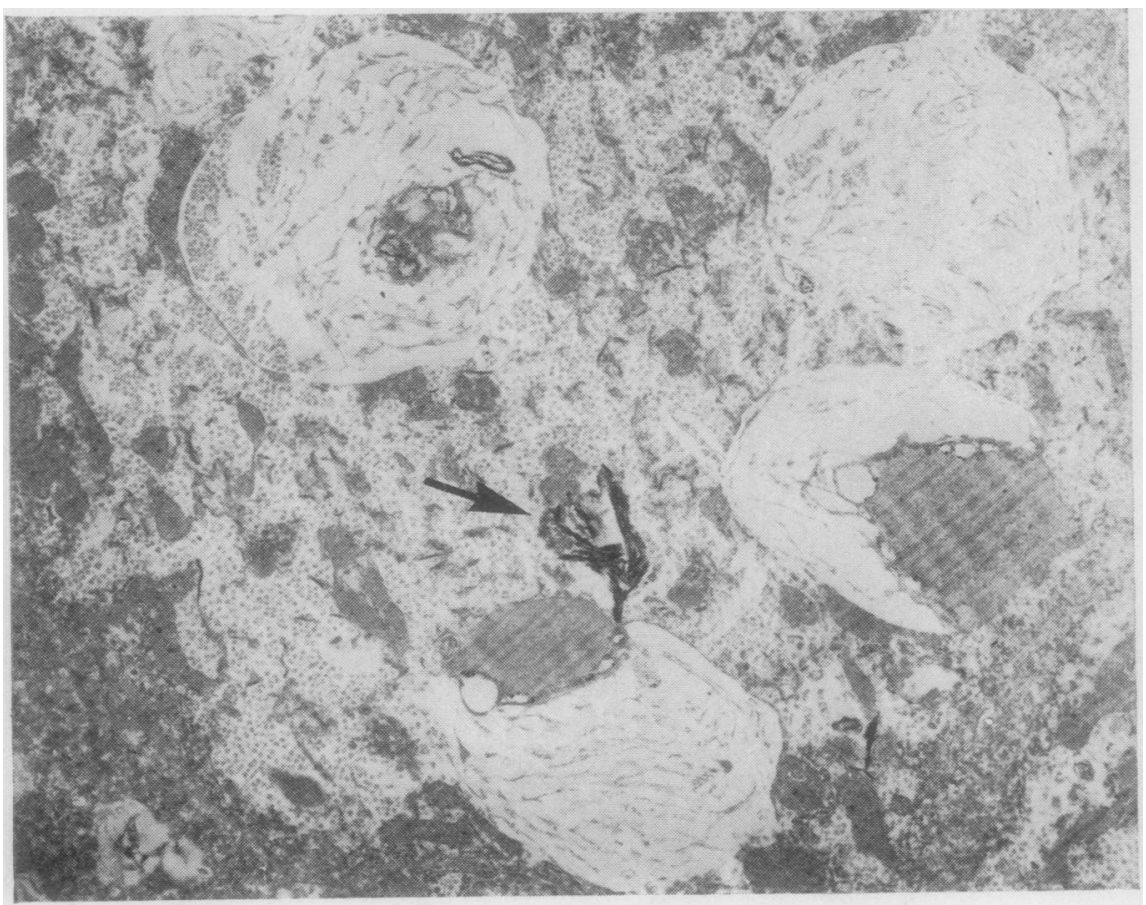

Fig 2 Human liver: membrane-bound vacuoles, containing lipid droplets and glycogen: crystal aggregates in cytoplasm (arrowed). Pb citrate and uranyl acetate $\times 10000$. 


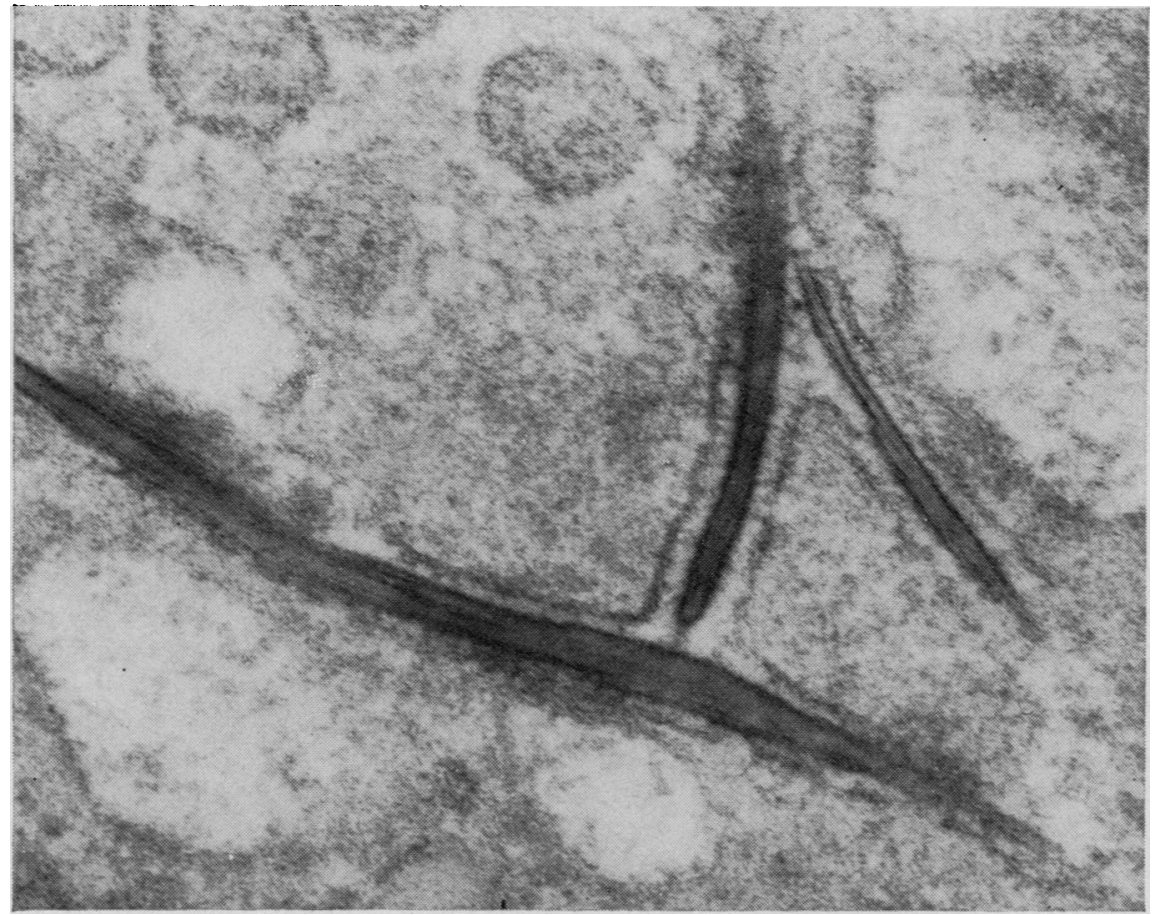

Fig 3 Human liver: sublaminated structure of crystal surrounded by $a$ unit membrane. $P b$ citrate and uranyl acetate $\times 160000$.

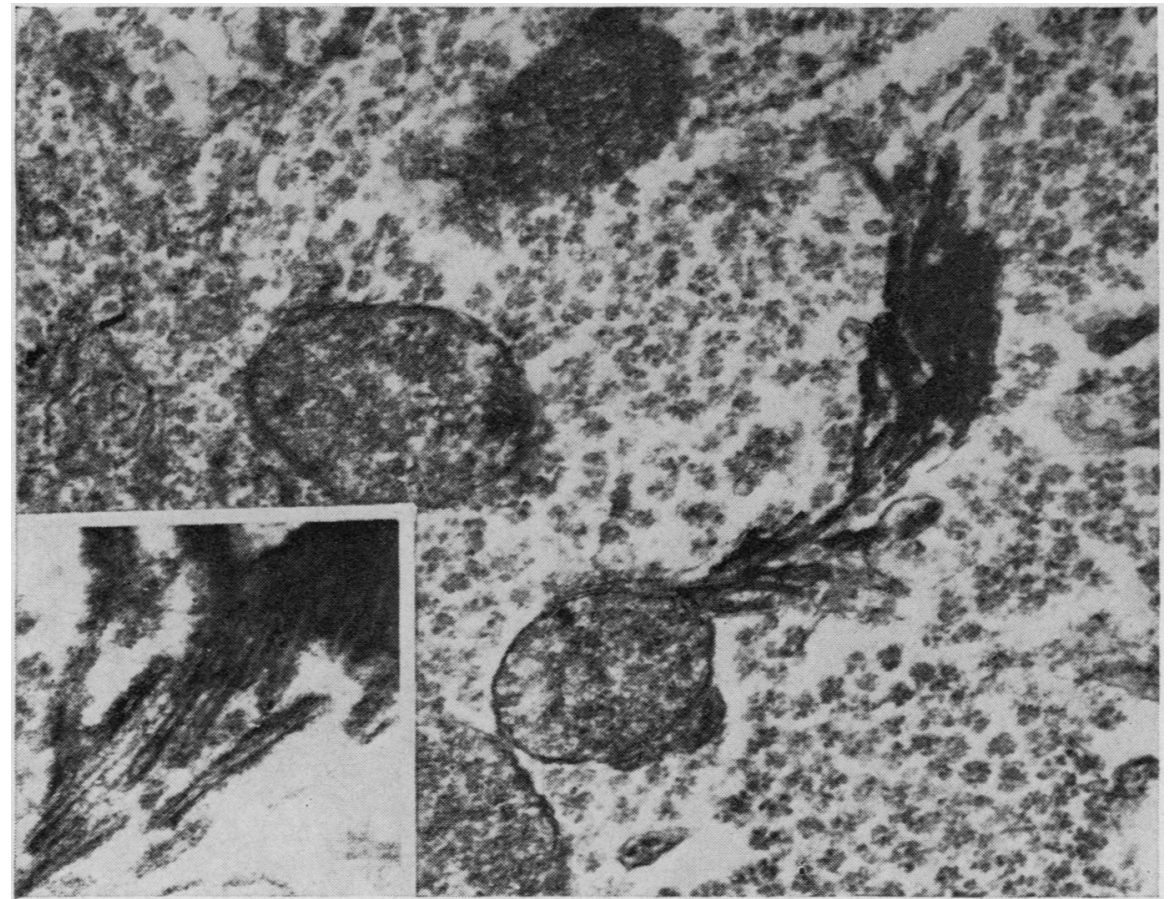

Fig 4 Human liver: crystals lying free in cytoplasm, possibly related to mitochondrion. $\mathrm{Pb}$ citrate and uranyl acetate $\times 42000$. (Inset $\times 126000$.) 


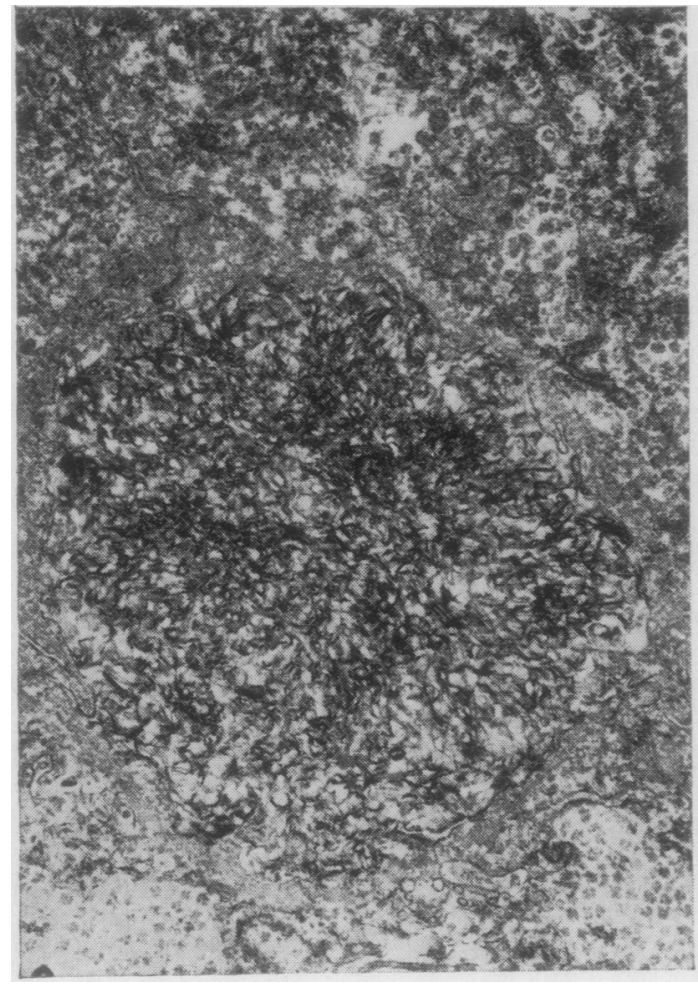

Fig 5 Human liver: dilated canaliculus, containing thrombus of crystals and granular material. $\mathrm{Pb}$ citrate and uranyl acetate $\times 24000$.

contained electron-dense granules $40-60 \mathrm{~nm}$ dia- $\bar{C}$ meter. Lipid droplets were present, some within $\frac{\bar{G}}{\bar{n}}$ membrane-bound, low-density structures also con- $\frac{\bar{\rho}}{\bar{\rho}}$ taining lamellar structures and particles of glycogen $\_$ (fig 2). Densely osmiophilic vacuolated bodies, some having a myelin substructure, were also seen. $\vec{\circ}$ Crystals, usually forming aggregates, were present:in the cytoplasm (fig 2). Each crystal had a dense $\vec{\omega}$ border 3-8 $\mathrm{nm}$ in thickness, and a less dense centre? comprising two or more layers $3 \mathrm{~nm}$ thick. They had a diameter of 30 to $120 \mathrm{~nm}$, and a length of 0.5 to $N$ $1.5 \mu$. Some were enclosed by a unit membrane con- -0 tinuous with the endoplasmic reticulum (fig 3);8 others appeared in close relationship to the outer ${ }^{\infty}$ membrane of mitochondria (fig 4); some were within the periphery of lipid droplets.

The canaliculi showed variable dilatation, blunt $-\mathscr{D}$ ing, and loss of villi, and the formation of micro- $\frac{-}{\mathrm{D}}$ villous blebs. Granular material and lamellar bodies 3 were present in the lumen. Many canaliculi were $\Phi$ occluded by thrombi, measuring up to $14 \mu$ diameter, $-\vec{\varphi}$ and containing granular material and crystals whigh $\varphi$ had the same appearance as those seen in the cyteplasm (fig 5).

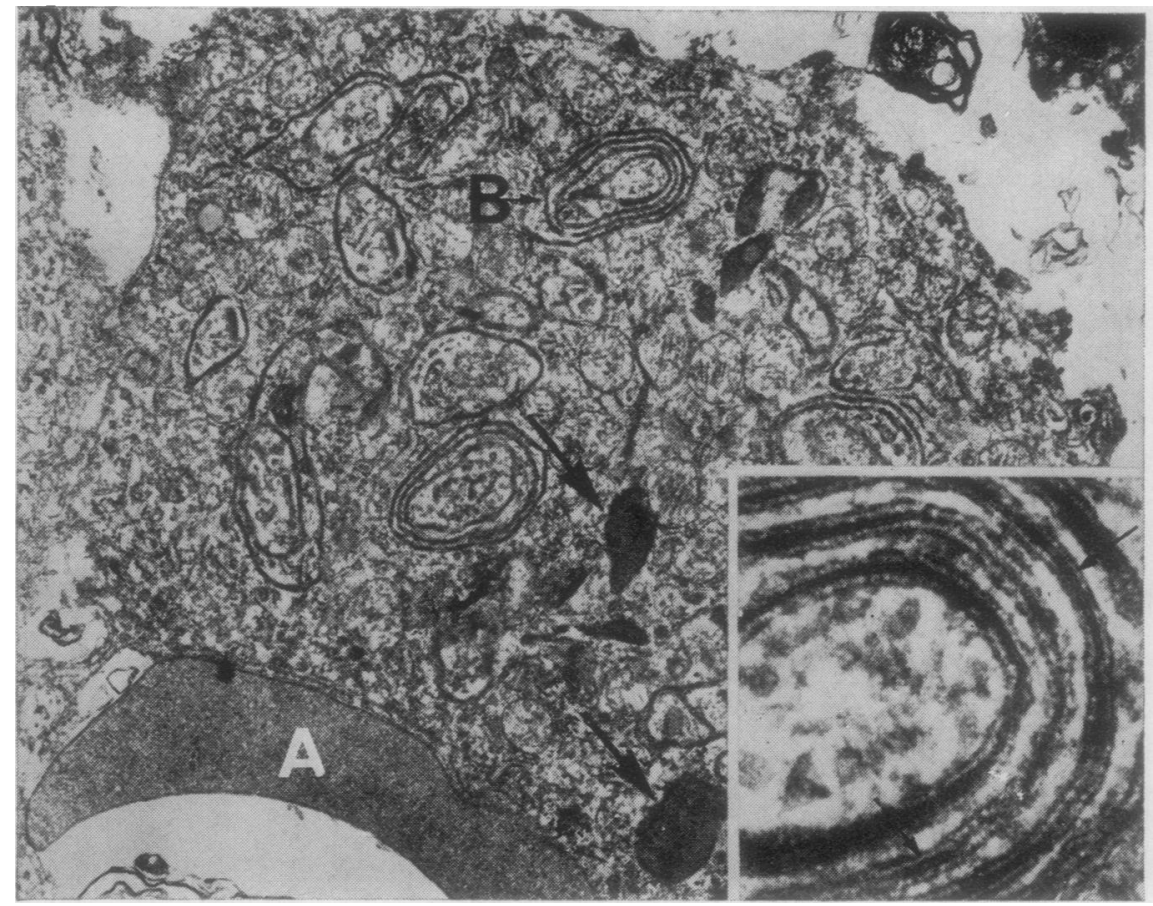

Fig 6 Human liver: part of Kupffer cell within which is a thrombus containing bile $(A)$; vacuoles containing lipid and crystals (arrowed), and whorls of crystals bounded by $a$ unit membrane ( $B)$. $P b$ citrate and uranyl acetate $\times 16000$. Inset: crystals (arrowed) within unit membrane $\times 50000$. 


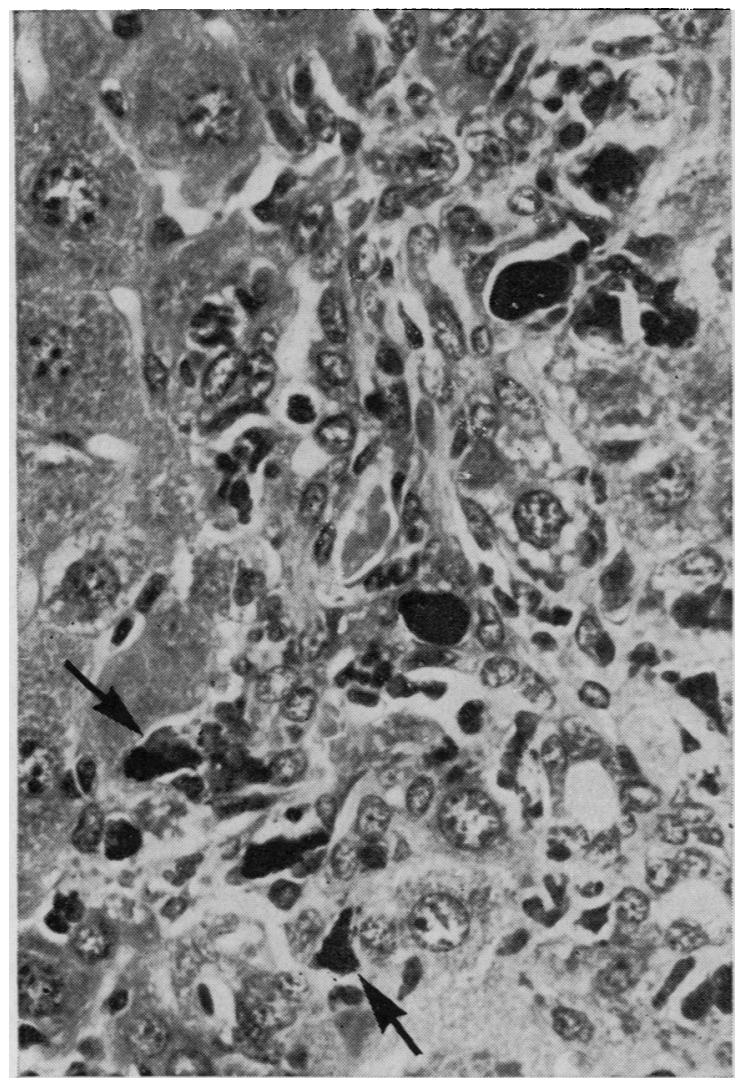

Fig 7a

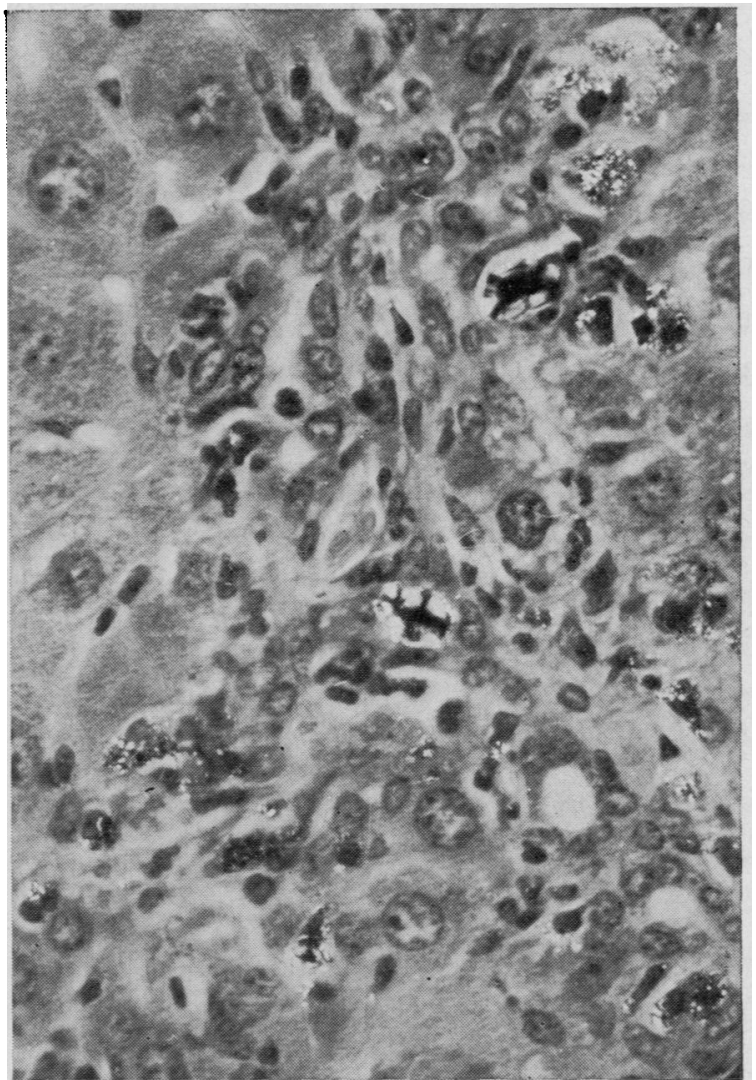

Fig $7 b$

Fig 7a Mouse liver: portal tract with thrombi in bile ducts, bile duct proliferation, pigment (arrowed) in adjacent Kupffer cells. $H \& E \times 140$.

Fig $7 \mathrm{~b}$ Viewed under polarized light: birefringent granules and Maltese crosses.

In the cytoplasm of the Kupffer cells there were numerous phagolysosomes, containing lipid and crystals at the periphery; whorls of crystals contained within a unit membrane were also present (fig 6). Some cells contained inclusions similar to the canalicular thrombi.

No portal tracts were present in the material.

\section{MOUSE LIVER AFTER ADMINISTRATION OF GRISEOFULVIN}

\section{Light microscopy}

Forty-eight hours after starting griseofulvin treatment there was a marked increase in mitotic activity of hepatocytes. Small dark brown granules also appeared and were initially situated on the canalicular side of the hepatocyte. Kupffer cells were normal.

At 96 hours there were a few foci of eosinophilic necrosis, associated with polymorphonuclear leuco- cytes. Proliferation of bile ductules had occurred, and some extended into the parenchyma at the edge of the limiting plate.

At seven days dark brown thrombi appeared in the canaliculi; they were also present in ductules and bile ducts in the portal tracts, where they were associated with a mild infiltration of lymphocytes (fig 7a).

After 10 days pigment accumulated in Kupffer cells and multinucleate cells were present. There was considerable variation in the amount of pigment formed in each liver. Granules of pigment were identified in vessels in the portal tracts of livers containing abundant pigment. Extensive foci of necrosis appeared. Groups of hepatocytes showed vacuolation of cytoplasm with the nucleus initially remaining intact; subsequently the cells dissolved and pigment was liberated, which was associated with a mild polymorphonuclear cell infiltration.

Viewed between crossed polars with a first order 
quartz red compensator in position weakly positively birefringent crystals appeared in the pigment granules of the hepatocytes at $\mathbf{4 8}$ hours. The bile duct and canalicular thrombi showed a 'Maltese cross' birefringence, and smaller 'Maltese crosses' were seen in the hepatocytes (fig 7b).

Examination using ultraviolet light showed a diffuse but rapidly fading red autofluorescence, first visible at $\mathbf{4 8}$ hours. The centres of the thrombi did not fluoresce but persistent fluorescence occurred around the periphery. There was also persistent fluorescence in the larger hepatocyte granules and Kupffer cell pigment. A proportion of red cells, especially in the central veins, showed moderate fluorescence. The gallbladder mucosa was also fluorescent.

All other tissues examined, including the spleen and bone marrow, showed no abnormalities.

\section{Electron microscopy of hepatocytes}

Changes were first observed in the mitochondria at 48 hours. There was marked size variation, with an $18 \%$ increase in average length, and the largest measured $4 \mu$ in length. Swelling, separation of cristae, bizarre shapes, and segmented mitochondria were seen (fig 8). Many appeared to have undergone degeneration and were converted to osmiophilic ring-like bodies with a myelin substructure. Later, the mitochondria again became more uni- form and rounded and peroxisomes containing paracrystalline inclusions appeared (fig 9). Occa- 믐 sional electron-dense granules were seen in the mitochondrial matrix, but these were less numerous $\underset{\vec{D}}{\vec{P}}$ than those in the human liver. There was some dila- $\bar{O}$ tation of the cisternae of the rough endoplasmic 듬 reticulum in the early stages; the Golgi apparatus $\frac{\overline{\bar{F}}}{\overrightarrow{\frac{\sigma}{2}}}$ appeared normal and glycogen was present in nor- $\mathbb{Q}$ mal amounts. Osmiophilic vacuolated bodies were seen in the later stages.

Crystals lying free in the cytoplasm were first $\vec{\circ}$ observed at 72 hours. Subsequently they appeared $\overrightarrow{\vec{\omega}}$ as small aggregates, up to $2 \mu$ diameter, many of $\stackrel{\omega}{\omega}$ which were enclosed by a unit membrane continuous with the endoplasmic reticulum and were concentrated in the region adjacent to the canaliculus (fig 10). They were similar to those found in the human material but were smaller with an overall $\bigodot_{0}$ width of 6 to $40 \mathrm{~nm}$ and length of up to $0.5 \mu$ (fig 11). 을 There was a dense border and a centre comprising up to 10 or more layers $3 \mathrm{~nm}$ thick.

After eight days occasional canaliculi were dilated and lamellar material appeared in the lumen. Thereafter the dilatation became more extensive, with loss of villi and microvillous bleb formation (fig 9). Some of the canaliculi appeared lined by lamellar $\vec{\varphi}$ bodies composed of either degenerate villi or bile Aggregates of crystals appeared in the canalicuif. during the first week; subsequently thrombi cont?

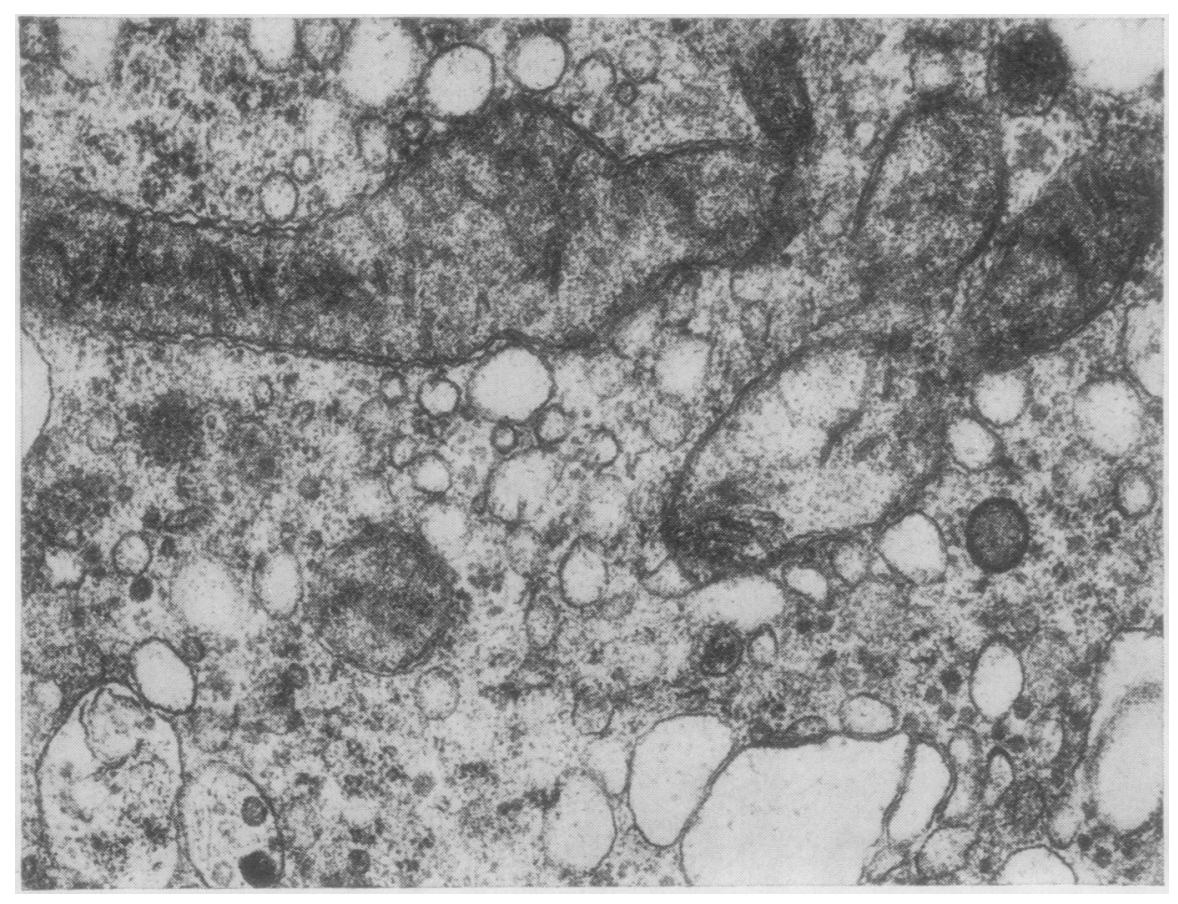

Fig 8 Mouse liver: elongated mitochondria, showing bizarre shapes and segmentation. $P b$ citrate and uranyl acetate $\times 30000$. 

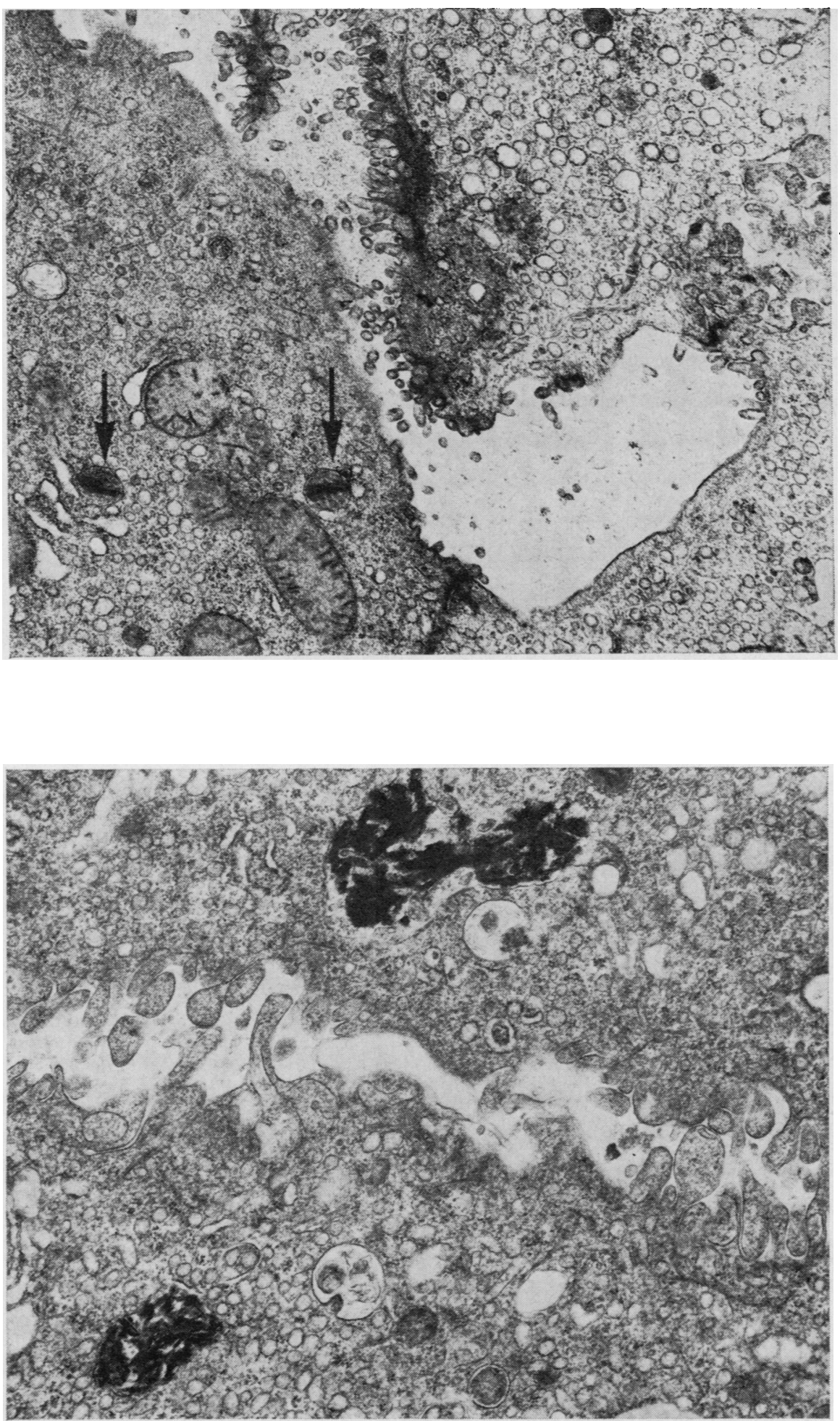

Fig 9 Mouse liver: dilated canaliculus with partial loss of villi. Paracrystalline inclusions in adjacent peroxisomes (arrowed). Pb citrate and uranyl acetate $\times 14500$.

Fig 10 Mouse liver: crystal aggregates within endoplasmic reticulum adjacent to canaliculus; microvillous bleb formation. $P b$ citrate and uranyl acetate $\times 20000$. 


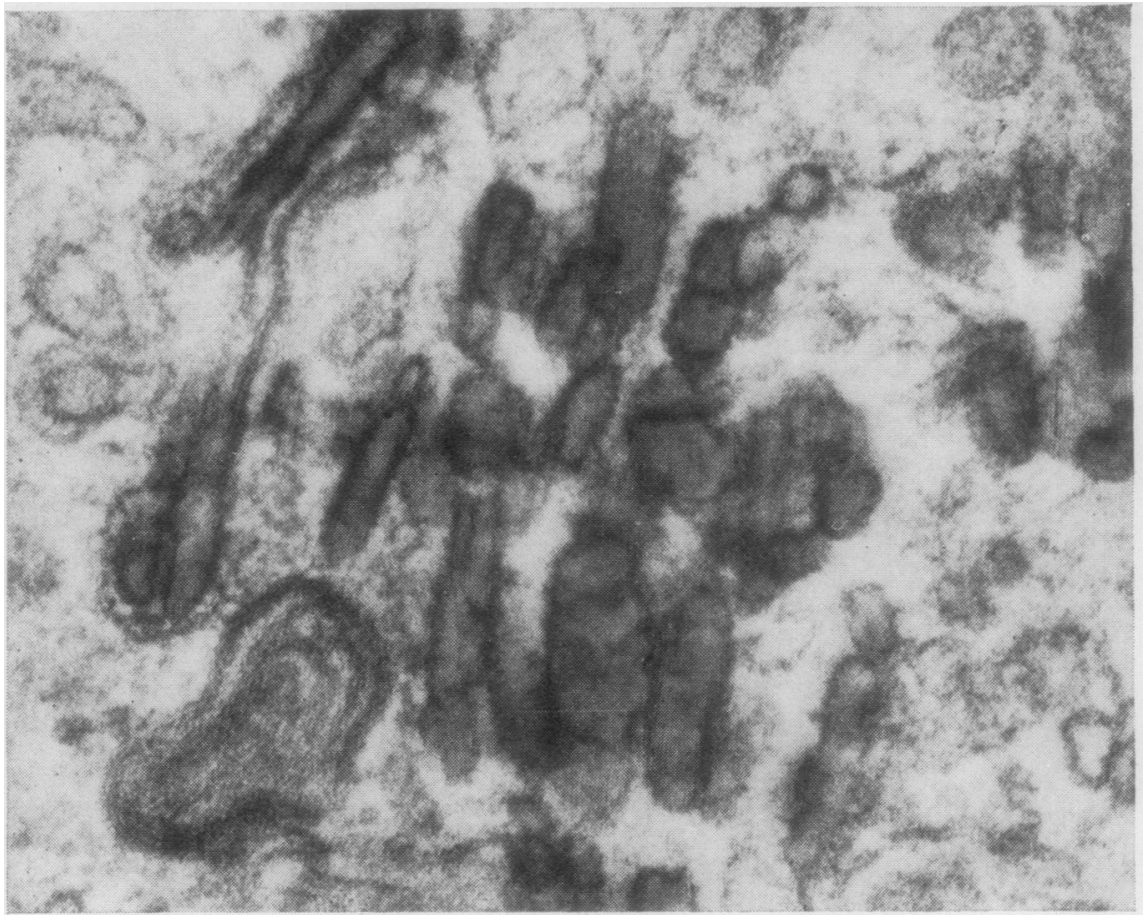

Fig 11 Mouse liver: $\overrightarrow{\vec{F}}$ crystals lying free in cytoplasm. Pb citrate and uranyl acetate $\times 136000$.

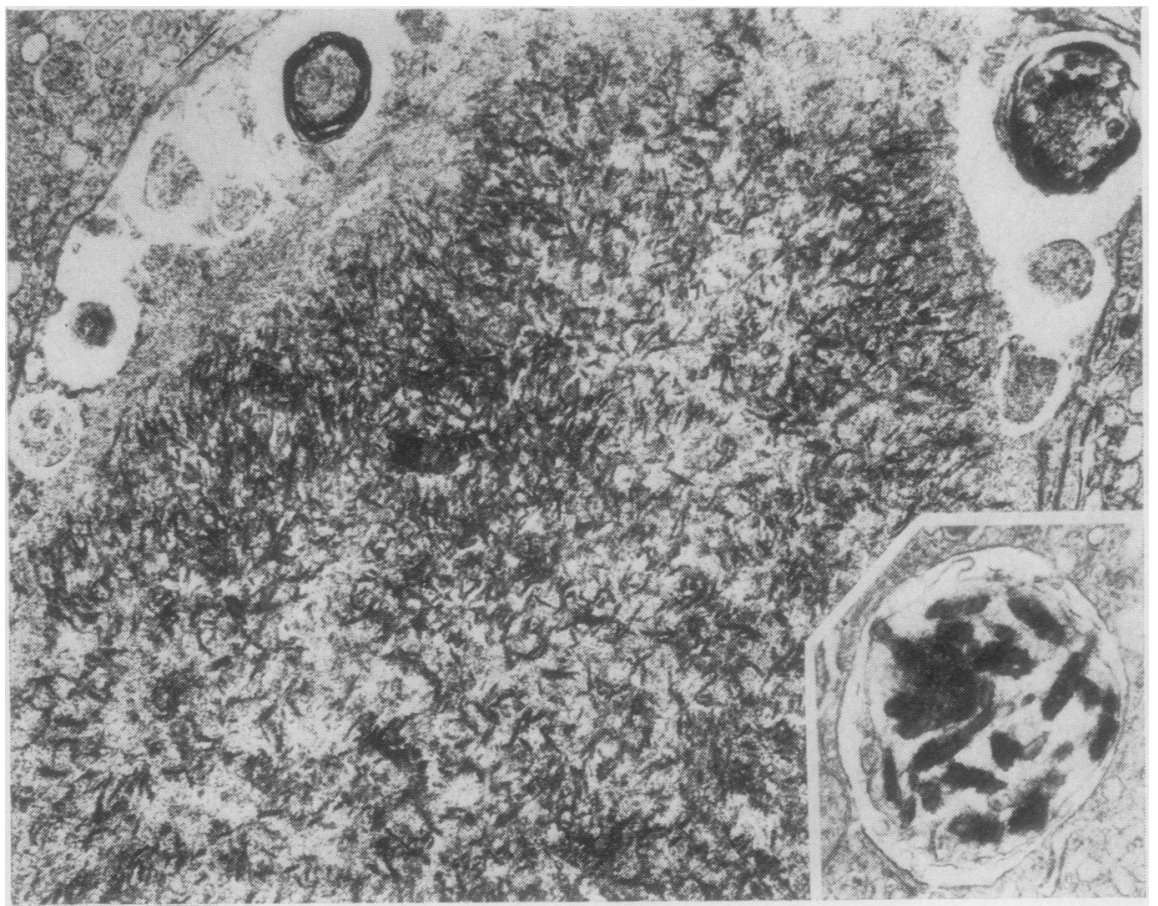

Fig 12 Mouse liver: thrombus in canaliculus, containing crystals and granular material. Lamellar bodies at the periphery. $\mathrm{Pb}$ citrate and uranyl acetate $\times 24000$.

(Inset: aggregate of crystals in canaliculus $\times 22000$.) 


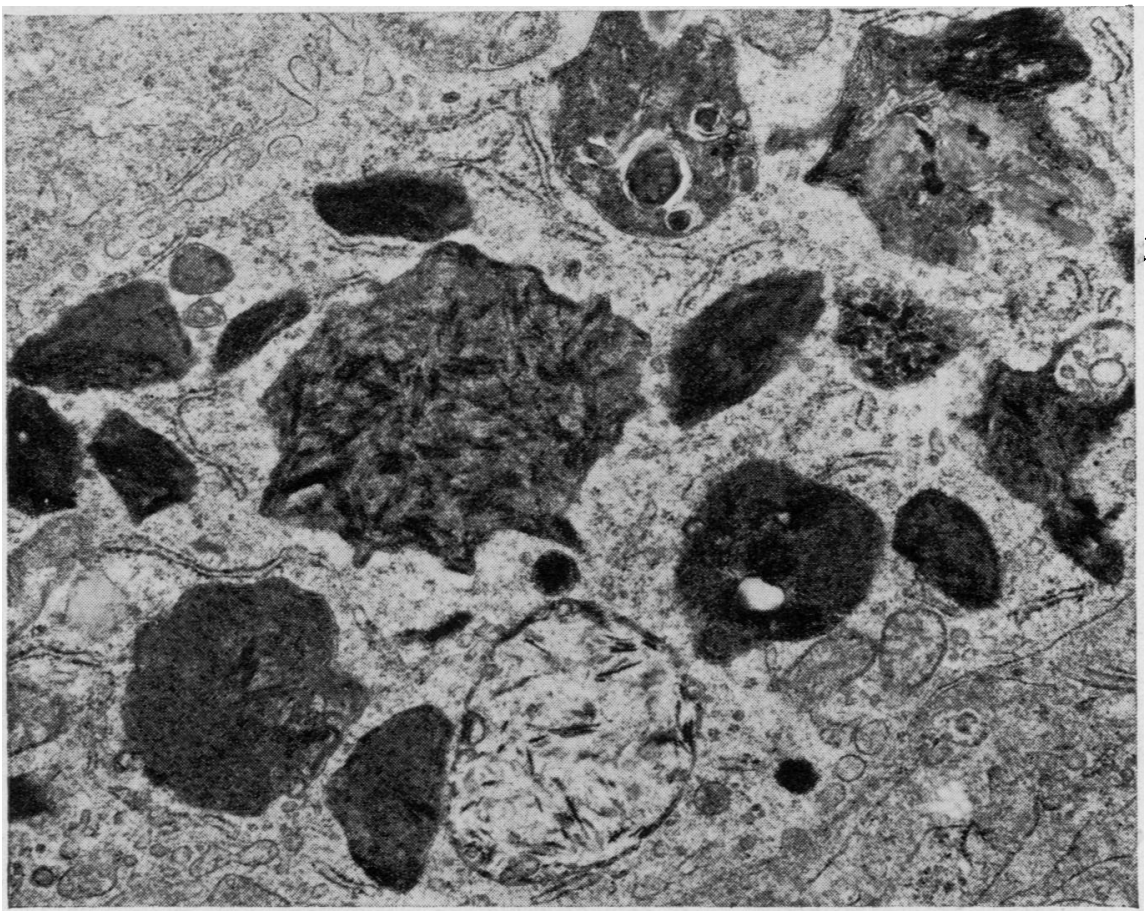

Fig 13 Mouse liver: crystals within heterophagocytic vacuoles in Kupffer cell. Pb citrate and uranyl acetate $\times 24000$

posed of crystals and granular material were present (fig 12) and their appearance varied according to the relative proportions of bile and crystalline material. Similar thrombi were seen in the bile ducts and ductules.

In the later stages crystals appeared in Kupffer cells usually within heterophagocytic vacuoles where they formed randomly arranged aggregates some of which were associated with lipid (fig 13). Some crystals were bounded by a unit membrane but the extensive whorls seen in the human Kupffer cells were not observed. Occasional inclusions, resembling canalicular thrombi with a high concentration of crystals, were present.

In well defined areas hepatocytes had undergone necrosis and polymorphonuclear leucocytes were present. Aggregates of crystals, some bounded by a unit membrane, were present in these areas.

Macrophages in the portal tracts contained large numbers of heterophagocytic vacuoles enclosing lipid and crystals.

\section{SPECTROSCOPY OF PIGMENT IN HUMAN AND MOUSE LIVER}

The emission spectrum of pigment in the human and animal livers was measured using a Zeiss pupillary spectroscope and found to be $630 \mathrm{~m} \mu$, and this was identical to that of a standard solution of protoporphyrin.

\section{Discussion}

The administration of griseofulvin to mice leads to an early increase of liver porphyrins, including protoporphyrin (Janoušek, 1970). Other changes include an increase in the excretion of faecal protoporphyrin and coproporphyrin followed by an increase in erythrocyte protoporphyrin concentration (De Matteis and Rimington, 1963). The effect of griseofulvin is due to inhibition of mitochondrial chelatase which leads to diminished incorporation of protoporphyrin into haem, lowering the level of the latter which normally acts as a negative feedback on porphyrin synthesis. There is therefore a rise in the ALA synthetase level (Nakao, Wada, Takaku, Sassa, Yano, and Urata, 1967), with an increase in all porphyrin intermediates and accumulation of protoporphyrin behind the block (fig 14).

ALA synthetase is located in themitochondria, and an increase in mitochondrial diameters from 25 to $50 \%$ has been described in the livers of DDC. treated guinea-pigs (Granick and Urata, 1963). The present study confirms that the earliest changes occur 
Negative Feedback

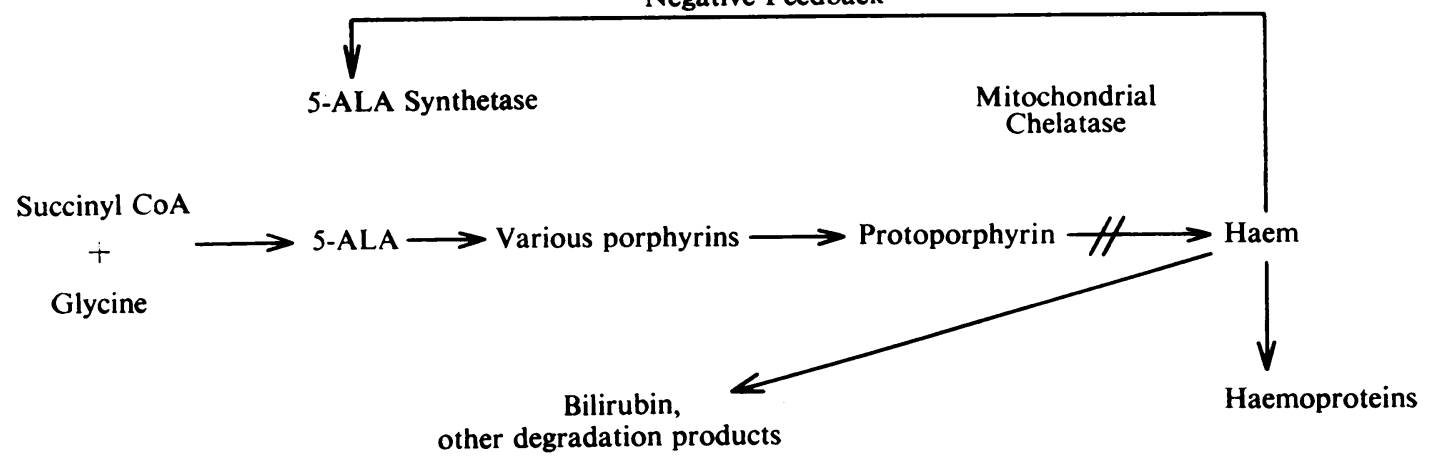

$\#-$ Site of action of griseofulvin

Fig 14 Inhibition of liver haem synthesis by griseofulvin.

in the mitochondria, with an $18 \%$ increase in average length.

Protoporphyrin diffuses from its site of formation at the mitochondrion throughout the hepatocyte cytoplasm and accounts for the rapidly fading fluorescence seen throughout the cytoplasm of the cells in the mouse livers. Our spectroscopic studies have confirmed that the crystals in the human and animal livers contain protoporphyrin. The factors determining their formation, however, remain unknown. The laminated structure with a dense outer border suggests incorporation of an additional component such as a lipid or protein. The early appearance of aggregates within membranes in the mouse liver suggests that the endoplasmic reticulum may contribute to their formation. Their location adjacent to the canaliculus and association with bile in the canaliculus suggest either that protoporphyrin may be handled by the cell in a similar manner to bilirubin or that it has an affinity for a constituent of bile. The increased concentration could lead to further crystallization and to the formation of thrombi, causing intrahepatic obstruction. The crystals may also cause direct damage to the canalicular lining.

The appearance of the necrosis in the mouse liver is not specific, but is not that of intrahepatic obstruction. Moreover, it occurs at a stage before significant numbers of thrombi are present. Perhaps a high concentration of protoporphyrin is toxic to the hepatocyte and a direct effect of griseofulvin cannot be excluded. There was no evidence of bacerial or viral infection.

The abnormalities present in the human liver closely resemble those seen in the later stages in the mouse liver. The early mitochondrial changes in the animal liver were not observed in the human,

whilst the absence of necrosis, and more extensive $\underset{\mathbb{D}}{\mathscr{D}}$ crystals within the Kupffer cell endoplasmic reticulum in the latter might suggest a lower concentration of protoporphyrin, accumulating over a long period of time.

It has been suggested that both erythropoiet\& $\vec{\theta}$ and liver porphyrin metabolism is disturbed in the griseofulvin-induced disease in mice (De Matte and Rimington, 1963). Nakao et al (1967) found evidence of raised ALA synthetase levels or inhibition of mitochondrial chelatase in the erythropoietic $\stackrel{2}{\mathscr{D}}$ spleen in this model and suggested that the increased erythrocyte protoporphyrin is of hepatic origin.

Isotope studies provide conflicting evidence about $\frac{O}{3}$ the principal site of disturbed porphyrin metabolism in the human disease (Gray, Kulczcka, Nicholson, Magnus, and Rimington, 1964; Scholnick, Marver, and Schmid, 1969; Schwartz, Johnson, Stephenson, Anderson, Edmundson, and Fusaro, 1970). In their $\frac{5}{3}$ clinical study of two cases, Cripps and MacEachern (1971) suggested that both liver and bone marrow were affected. The erythrocyte protoporphyrin levels in our case were lower than those in the latter $\frac{}{5}$ cases, whilst our stool protoporphyrin levels were $\frac{D}{0}$ higher. This may indicate a principal hepatic lesion in our case.

Using a chick liver embryo cell culture, Granick (1963) demonstrated the porphyria-inducing effect of griseofulvin and sex steroids. Although oestrogenic $\omega$ hormones do not cause increased porphyrin excre-울 tion in normal individuals it has been reported thate they may precipitate or aggravate acute intermittent $\Phi$ porphyria and porphyria cutanea tarda with eleva- + tion of liver ALA synthetase (Zimmerman, McMillin, $\frac{\square}{0}$ and Watson, 1966). An effect of these hormones in $\frac{\mathrm{O}}{\mathrm{D}}$ protoporphyria seems not to have been recorded. 
However, the pattern of porphyrin excretion and accumulation depends on the relative amounts of ALA synthetase and protoporphyrin utilization. Thus low doses of DDC produces porphyria in rats which is similar to human protoporphyria, whilst higher doses of DDC induce a condition similar to porphyria cutanea tarda (Magnus et al, 1969).

The morphological similarities between the animal human livers suggest a primary hepatic lesion in each case, but they do not provide information about the mechanisms leading to protoporphyrin accumulation. It is reasonable to suggest, however, that there may be cases within the group of erythrohepatic protoporphyrias where the principal lesion is in the liver. In the case reported here the pill may have elevated the liver ALA synthetase level sufficiently to cause accumulation of protoporphyrin in a previously abnormal but compensated system.

We wish to thank Dr P. R. Montgomery and Dr C. Ramsay for clinical information and material; Dr J. Landells for the liver biopsy; Mr Ken Swettenham and Mr Alan Gray for technical assistance; Professor I. A. Magnus, Dr F. De Matteis, and Professor I. Doniach for help and advice.

\section{References}

Barnes, H. D., Hurworth, E., and Millar, J. H. D. (1968). Erythropoietic porphyrin hepatitis. J. clin. Path., 21, 157-159.

Bloomer, J. R., Davidson, D. L., and Klatskin, G. (1973). Birefringent pigment is a diagnostic hepatic lesion in protoporphyria. Gastroenterology, 65, A-5/529.

Cripps, D. J., and MacEachern, W. N. (1971). Hepatic and erythropoietic protoporphyria. Arch. Path., 91, 497-505.

Cripps, D. J., and Scheuer, P. J. (1965). Hepatobiliary changes in erythropoietic protoporphyria. Arch. Path., 80, 500-508.

De Matteis, F., and Rimington, C. (1963). Disturbance of porphyrin metabolism caused by griseofulvin in mice. Brit. J. Derm., 75, 91-104.

Donaldson, E.M., McCall, A. J., Magnus, I. A., Simpson, J. R.,Caldwell, R. A., and Hargreaves, T. (1971). Erythropoietic protoporphyria: two deaths from hepatic cirrhosis. Brit. J. Derm.. 84, 14-24.

Granick, S. (1966). The induction in vitro of the synthesis of $\delta$-aminolevulinic acid synthetase in chemical porphyria: a response to certain drugs, sex hormones, and foreign chemicals. J. biol Chem., 241, 1359-1375.

Granick, S., and Urata, G. (1963). Increase in activity of \&-aminolevulinic acid synthetase in liver mitochondria induced by feeding of 3, 5- dicarbethoxy-1, 4-dihydrocollidine. J. biol. Chem., 238, 821-827.

Gray, C. H., Kulczycka, A., Nicholson, D. C., Magnus, I. A., and Rimington, C. (1964). Isotope studies on a case of erythropoietic protoporphyria. Clin. Sci., 26, 7-15.

Janousek, V. (1970). The early changes in experimental porphyria of mice induced by griseofulvin. Trans. St. John's Hosp. Derm. Soc., 56, 14-18.

Magnus, I.A., Jarrett, A., Prankerd, T. A. J., and Rimington, C. (1961). Erythropoietic protoporphyria: a new porphyria syndrome with solar urticaria due to protoporphyrinaemia. Lancet, 2, $448-451$.

Magnus, I. A., Porter, A. D., McCree, K. J., Moreland, J. D., and Wright, W. D. (1959). A monochromater: an apparatus for the investigation of the responses of the skin to ultra-violet, visible and near infra-red radiation. Brit. J. Derm., 71, 261-266.

Magnus, I. A., Roe, D. A., and Bhutani, L. K. (1969). Factors affecting the induction of porphyria in the laboratory rat: biochemical and photobiological studies using diethyl 1, 4-dihydro-2, 4, 6-trimethylpyridine-3, 5-dicarboxylate (DDC) as a porphyrogenic agent. J. invest. Derm., 53, 400-413.

Nakao, K., Wada, O., Takaku, F., Sassa, S., Yano, Y., and Urata, G. (1967). The origin of the increased protoporphyria in erythrocytes of mice with experimentally induced porphyria. J. Lab. clin. Med., 70, 923-932.

Porter, F S., and Lowe, Betty A. (1963). Congenitalery thropoietic protoporphyria. I. Case reports, clinical studies and porphyrin analysis in two brothers. Blood, 22, 521-531.

Roe, D. A., Krook, L., and Wilkie, B. N. (1970). Hepatic protoporphyria in weanling pigs. $J$. invest. Derm., 54, 53-64.

Schmid, R., Schwartz, S., and Watson, C. J. (1954). Porphyrin content of bone marrow and liver in the various forms of porphyria. Arch. intern. Med., 93, 167-190.

Schmidt, D., and Stich, W. (1971). Erythropoetische Protoporphyrie mit Porphyrinurie. Blut, 22, 202-210.

Scholnick, P., Marver, H., and Schmid, R. (1969). Erythropoietic protoporphyria: a misnomer. Clin. Res., 17, 278.

Schwartz, S., Johnson, J. A., Stephenson, B. D., Anderson, A. S., Edmondson, P. R., and Fusaro, R. M. (1970). Erythropoietic defects in protoporphyria: a reevaluation of early peak labelling. J. Lab. clin. Med., 76, 893-894.

Thompson, R. P. H., Molland, E. A., Nicholson, D. C., and Gray, C. H. (1973). 'Erythropoietic' protoporphyria and cirrhosis in sisters. Gut, 14, 934.

Waterfield, M .D., Favero, A. del, and Palfrey, A. J. (1969). Electronmicroscopic changes in the livers of mice treated with the porphyrinogenic agent 1 ,4-dihydro-3, 5-dicarbethoxycollidine. $J$. Path., 98, 151-154.

Weston-Hurst, E., and Paget, G. E. (1963). Protoporphyrin, cirrhosis and hepatomata in the livers of mice given Griseofulvin. Brit.J. Derm., 75, 105-112.

Zimmerman, T. S., McMillin, J. M., and Watson, C. J. (1966). Onset of manifestations of hepatic porphyria in relation to the influence of female sex hormones. Arch. intern. Med., 118, 229. 240. 